\title{
Revisão de Aspectos Conceituais, Teóricos e Metodológicos da Empatia
}

\author{
Review of the Conceptual, \\ Theoretical and Methodological Aspects of Empathy \\ Revisión de Aspectos de Conceptuales, \\ Teoréticos y Metodológicos de la Empatía
}

Leonardo Rodrigues Sampaio Universidade Federal do Vale do São Francisco

Cleonice Pereira dos

Santos Camino

Universidade Federal da Paraíba

Antonio Roazzi

Universidade Federal de

Pernambuco

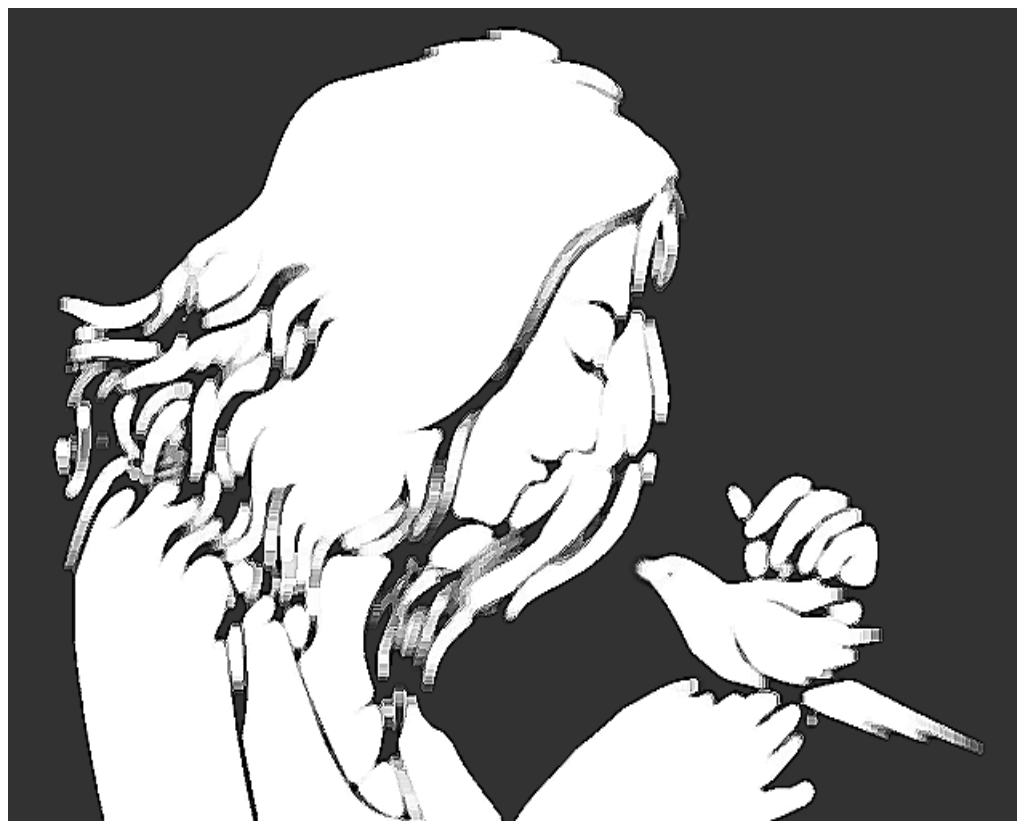


Resumo: A empatia foi objeto de estudo de diversos campos do saber, como a estética, a Filosofia, a Sociologia e a Psicologia. No que se refere a esta última, a empatia tem sido discutida e investigada principalmente por pesquisadores das áreas clínica, social e do desenvolvimento. O objetivo do presente trabalho é apresentar uma revisão da literatura sobre a empatia, enfocando aspectos teóricos, conceituais e metodológicos. Inicialmente, serão levantadas questões sobre a polissemia do termo empatia, sobre as controvérsias a respeito da dimensionalidade desse constructo e alguns problemas teórico-metodológicos atuais nesse campo de estudos. Em seguida, serão apresentadas as principais estratégias de investigação usadas na pesquisa sobre a empatia e os resultados de estudos empíricos que abordam reações afetivas vicárias, caracterizadas como sentimentos empáticos. Por fim, serão tecidas algumas considerações a respeito da necessidade de resolução dos problemas teórico-metodológicos citados, da realização de mais trabalhos empíricos e teóricos sobre a empatia no Brasil e das perspectivas futuras de investigação da empatia.

Palavras-chave: Empatia. Conceitos. Teoria. Pesquisa.

\begin{abstract}
Empathy was object of study of diverse fields of knowledge as aesthetic, philosophy, sociology and psychology. In relation to the last one, empathy has been discussed and investigated mainly for researchers of clinical, social and developmental areas. The main objective of the present work is to present a review of the literature on empathy, focusing the theoretical, conceptual and methodological aspects proper to the field of studies of empathy. Questions related to the polysemy of the term empathy are used, and discussion concerning the dimensionality of this construct and some theoretical and methodological problems will be raised and discussed. Empirical studies and some research strategies used on the empathy field will be presented. Eventually, we will present some considerations regarding the necessity of resolution of the aforementioned problems, the need of more research on empathy in Brazil and the future perspectives of research.
\end{abstract}

Keywords: Empathy. Concepts. Theory. Research.

Resumen: La empatía fue objeto de estudio de diversos campos del saber, como la estética, la Filosofía, la Sociología y la Psicología. En lo que se refiere a ésta última, la empatía ha sido discutida e investigada principalmente por investigadores de las áreas clínica, social y del desarrollo. El objetivo del presente trabajo es presentar una revisión de la literatura sobre la empatía, enfocando aspectos teóricos, conceptuales y metodológicos. Inicialmente, serán levantadas cuestiones sobre a polisemia del término empatía, sobre las controversias a respeto de la dimensionalidad de ese constructo y algunos problemas teorético-metodológicos actuales en ese campo de estudios. Enseguida, serán presentadas las principales estrategias de averiguación usadas en la pesquisa sobre la empatía y los resultados de estudios empíricos que abordan reacciones afectivas vicarias, caracterizadas como sentimientos de empatía. Por fin, serán montadas algunas consideraciones a respeto de la necesidad de resolución de los problemas teorético-metodológicos citados, de la realización de más trabajos empíricos y teóricos sobre la empatía en Brasil y de las perspectivas futuras de averiguación de la empatía.

Palabras clave: Empatía. Conceptos. Teoría. Pesquisa.

O termo empatia deriva da palavra grega "empatheia", que significa "paixão" ou "ser muito afetado", e sua utilização no campo da estética foi muito propagada por autores como Lipps, Brentano e Robert Vischer (Enz \& Zoll, 2006). Esses autores descreveram o que hoje se conhece como empatia como um processo de imitação interna chamado de Einfühlung, ocorrido durante a apreciação de objetos de arte e no qual a projeção do self em obras artísticas fazia com que sentimentos de admiração e unicidade surgissem nos observadores dessas obras. Através do Einfühlung, propriedades subjetivas como nobreza, elegância e poder podiam ser sentidas como se pertencessem às próprias obras de arte, tal como se estas fossem seres com vida (Baldwin, 1913).

No que diz respeito à Psicologia, o primeiro autor a traduzir o termo Einfühlung por empathy foi Titchener, em 1909. Na concepção desse estruturalista norte-americano, o conceito de Einfühlung descrevia a capacidade de conhecer a consciência de outra pessoa e de raciocinar de maneira análoga a ela através de um processo de imitação interna, sendo que, por meio dessa capacidade, pessoas com o mesmo nível intelectual e moral poderiam compreender umas às outras (Wispé, 1986). 
Para Rogers (1979/2001a), podia-se falar de uma compreensão empática quando se vai além de um entendimento "exterior" sobre os pensamentos e sentimentos da outra pessoa, chegando a compreendê-la "de dentro".
No início do século XIX, a idéia da empatia como uma característica pela qual alguém identifica o que está na consciência de outra pessoa já era profundamente utilizada e dominava alguns campos da Psicologia e das Ciências sociais. Nessa época, nenhuma outra área teve interesse maior por esse construto do que a Psicologia da personalidade. Esse entusiasmo fez com que os pressupostos da estética fossem modificados, pois, enquanto os críticos de arte sugeriam que por meio da empatia (Einfühlung) o self era objetivado nas obras de arte, os psicólogos da personalidade afirmavam que, durante o processo de empatia, um objeto qualquer era subjetivado pela percepção do observador. Nessa direção, os psicólogos sustentavam que a empatia era uma capacidade através da qual as pessoas compreendiam umas às outras, sentiam e percebiam o que acontece com os outros, como se elas mesmas estivessem vivenciando as experiências alheias.

Já no século $X X$, até a metade da década de 40, o conceito de empatia foi objeto de reflexão teórica de autores como Freud, Alport e Reik (Wispé, 1987), mas poucas investigações empíricas haviam sido realizadas até então. Foi só no início da década de 50 que a empatia passou a ser investigada com maior aprofundamento e aplicada na prática psicoterapêutica a partir da iniciativa de Carl Rogers. Suas descobertas nesse campo deramIhe subsídios para que ele desenvolvesse uma modalidade psicoterápica que ficou mundialmente conhecida como Abordagem Centrada na Pessoa (ACP). Nesta, o terapeuta busca estabelecer um clima terapêutico adequado, desenvolvendo sentimentos empáticos pelo cliente, propiciando-lhe um ambiente de aceitação incondicional e sendo extremamente autêntico na comunicação de seus comportamentos, pensamentos e sentimentos.

A empatia assumiu importância fundamental na teoria rogeriana quando esse autor afirmou ser necessário que o terapeuta desenvolvesse uma compreensão empática pelo cliente. Assim, a empatia era vista por Rogers não apenas como uma resposta reflexa ao comportamento do outro mas também como uma habilidade aprendida/ desenvolvida que envolve o estabelecimento de vínculos cognitivo-afetivos entre duas ou mais pessoas, durante os quais alguém se permite, deliberadamente, sensibilizar-se e envolver-se com a vida privada de outros (Rogers, 1985/2001b).

Para Rogers (1979/2001a), podia-se falar de uma compreensão empática quando se vai além de um entendimento "exterior" sobre os pensamentos e sentimentos da outra pessoa, chegando a compreendê-la "de dentro". Isso implica a sensibilização do terapeuta pelo relato do cliente, a apreensão e a compreensão de seus estados internos, sem fazer nenhum julgamento de valor sobre a subjetividade do outro.

A insistência de Rogers em estudar empiricamente a empatia levou-o a pesquisar profundamente o processo clínico através do qual as respostas afetivas vicárias são produzidas e a trabalhar na elaboração de técnicas de mensuração que poderiam ser utilizadas para avaliar o nível de empatia das pessoas. Foi justamente enquanto Rogers desenvolvia sua abordagem centrada na pessoa que as mais importantes investigações sobre a empatia foram realizadas no âmbito da Psicologia da personalidade (Wispé, 1987).

No que diz respeito à Psicologia social, a partir da década de 60, diversos estudos (Batson, Duncan, Ackerman, Buckley, \& Birch, 1981; Coke, Batson, \& McDavis, 1978; Krebs, 1975) foram desenvolvidos para investigar comportamentos de ajuda, distribuição e mediação, tentando explicá-los através de construtos motivacionais como o altruísmo, as disposições pessoais, a dependência e a própria empatia. Apesar de haver divergências 
Segundo Hoffman

(1987, 1991), a

empatia está

diretamente

relacionada ao

desenvolvimento de um senso cognitivo sobre a existência de outras pessoas, o qual, por sua vez, se encontra ligado

ao processo de

diferenciação do self. conceituais no que se refere a termos como empatia, simpatia e compaixão, a idéia de que esses construtos estariam relacionados a aspectos motivacionais da vida em sociedade foi amplamente utilizada por psicólogos sociais das mais diversas correntes teóricas. De maneira geral, esses autores estavam interessados em saber porque as pessoas se engajam em comportamentos de ajuda e em quais circunstâncias estes se tornam mais prováveis, bem como qual seria o papel da empatia nesse processo.

Quanto à Psicologia do desenvolvimento, além dos trabalhos clássicos de Baldwin sobre o processo de ejeção (Baldwin, 1913), destacam-se as pesquisas de autores como Susan Isaacs e Lois Murphy (Murphy, 1937), as quais investigaram capacidades empáticas ligadas à tomada de perspectiva em crianças. Norma Feshback e Kiki Roe (Feshback \& Roe, 1968), considerando a capacidade de atribuir corretamente a emoção que o outro sente como um componente necessário para a empatia, desenvolveram um teste para crianças que ainda é amplamente utilizado nos dias de hoje, o Feshbach Affective Situation Test for Empathy (FASTE). Utilizando o FASTE, essas autoras demonstraram que crianças de 6 e 7 anos reconheciam mais facilmente as emoções do outro do que sentiam as emoções do outro, e, além disso, que as respostas empáticas das crianças eram influenciadas pela similaridade entre o seu sexo e o sexo da pessoa observada, e que, nessa idade, parecia não haver diferenças de sexo relacionadas à reatividade afetiva em situações que envolviam medo, alegria, tristeza e raiva.

Outros autores têm proposto que a empatia deve ser analisada a partir de uma perspectiva psicogenética e evolutiva, sendo compreendida como um tipo de experiência subjetiva multifacetada. Dentre estes, destaca-se o psicólogo norte-americano Martin L. Hoffman, que define a empatia como "...uma resposta afetiva mais apropriada à situação de outra pessoa do que à sua própria situação" (Hoffman, 1987, p. 48). Com essa conceituação, Hoffman propõe que a empatia, em lugar de ser um processo de encontro exato de emoções entre duas pessoas, é uma resposta vicária à imagem mental que alguém tem do sofrimento de outrem, o que implica um certo grau de afastamento entre eles.

Segundo Hoffman $(1987,1991)$, a empatia está diretamente relacionada ao desenvolvimento de um senso cognitivo sobre a existência de outras pessoas, o qual, por sua vez, se encontra ligado ao processo de diferenciação do self. Além disso, a associação entre os sentimentos produzidos durante os episódios empáticos e os níveis de desenvolvimento sociocognitivo produz mudanças na maneira como os indivíduos irão sentir subjetivamente a empatia. Em idades muito precoces, nas quais ainda não existe distinção cognitiva entre o self e o outro, as crianças podem ter sentimentos empáticos ao testemunhar a angústia do outro, como se aquele sofrimento estivesse ocorrendo com elas mesmas. Assim, ao ver um colega se machucar e chorar, a criança pode chorar como se ela mesma tivesse se machucado. A esse tipo de sentimento, que produz sensações de incômodo ou desconforto no self, Hoffman (1989) dá o nome de angústia empática.

De acordo com Hoffman (1991), a partir do desenvolvimento da consciência sobre a permanência dos objetos e da diferenciação entre o self e o outro, parte da angústia empática é transferida para as imagens separadas do self e do outro, as quais se encontram em processo de construção. Assim, a criança passa a reconhecer que as experiências do outro são distintas das suas próprias, mas a subjetividade do outro ainda permanece desconhecida, e ela acredita que o outro possui estados internos iguais aos seus. Nessa fase, uma criança pode pedir à 
sua própria mãe para confortar outra criança que está chorando, mesmo quando a mãe da outra também está presente.

Com o desenvolvimento do sentido cognitivo do outro e com a transferência de parte dos afetos empaticamente sentidos no self para a imagem do outro, a angústia empática pode ser parcialmente transformada em um novo tipo de sentimento, chamado de angústia simpática. Por meio desse sentimento, o sujeito experiencia um sentimento de piedade ou compaixão pela vítima e sente necessidade não só de aliviar sua própria angústia ou sofrimento, mas também um desejo claro de ajudar o outro (Hoffman, 1987, 1991). É justamente essa característica que diferencia a angústia empática da angústia simpática, pois, enquanto a primeira se centra claramente no self, a segunda é direcionada ao outro, estando eminentemente ligada aos comportamentos pró-sociais. Hoffman afirma que, apesar de a angústia empática parecer mais "egoísta", ela tem um papel importante para os comportamentos pró-sociais, pois, para aliviar a própria angústia, alguém pode ter que, necessariamente, aliviar a angústia do outro.

Nessa direção é que Hoffman (Hoffman, 1991), diferentemente de outros autores, afirma haver diferenças qualitativas nos componentes afetivos da empatia, principalmente no que diz respeito à natureza da experiência subjetiva do observador e às motivações produzidas pelos sentimentos empáticos. A teoria de Hoffman serviu como inspiração para diversos trabalhos que objetivavam investigar as relações entre a empatia e o desenvolvimento sociocognitivo (Batson et al., 1981; Camino \& Camino, 1996; Davis, 1983; Eisenberg, Zhou, \& Koller, 2001), mas muitos dos pressupostos desse autor continuam não testados empiricamente.

Seguindo uma linha de pensamento semelhante à de Hoffman, Batson, Fultz e
Schoenrade (1987) formularam uma teoria na qual distinguem conceitualmente dois tipos de reações afetivas vicárias, qualitativamente diferentes e com conseqüências motivacionais distintas: empatia e angústia pessoal. A primeira produziria motivação altruísta/pró-social, e a segunda mobilizaria um comportamento mais egoísta que poderia servir como base para a empatia, a depender das circunstâncias. Nessa direção, compreende-se haver uma aproximação entre os conceitos de angústia simpática de Hoffman e o de empatia, proposto por Batson et al.

Para comprovar a teoria de que os episódios empáticos podem produzir dois tipos de sentimentos qualitativamente distintos, Batson et al. (1987) conduziram seis estudos nos quais os respondentes deveriam avaliar os tipos de reação afetiva e a intensidade dessas reações, através de uma lista com 14 adjetivos (alarmed, grieved, upset, worried, disturbed, perturbed, distressed, troubled, sympathetic, moved, compassionate, tender, warm e softhearted). Através de análises fatoriais, esses pesquisadores observaram que os sete primeiros adjetivos compunham um fator que foi denominado angústia (distress), enquanto os sete últimos se organizavam em outro fator que foi chamado de empatia (empathy). Tais resultados demonstraram que havia diferenças qualitativas e quantitativas na avaliação que os respondentes faziam sobre o tipo de experiência afetiva vivenciada na situação experimental, o que reforçou a tese de que a empatia deve ser compreendida como um construto multidimensional.

Considerando os trabalhos de Batson (Batson et al., 1981; Batson et al., 1987) e de outros autores (Davis, 1983; Enz \& Zoll, 2006; Siu \& Shek, 2005), compreende-se que uma perspectiva multidimensional é mais coerente para a análise e a compreensão da empatia do que as perspectivas unidimensionais, uma vez que os estudos empíricos demonstram as inter-relações entre componentes 
cognitivos e afetivos e indicam que as pessoas experimentam diferentes tipos de experiências emocionais durante os episódios empáticos. Todavia, faz-se necessário um maior refinamento teórico-conceitual nesse campo de estudos, pois a revisão bibliográfica feita por Sampaio (2007) demonstra que, muitas vezes, termos como empatia, angústia pessoal, angústia empática, simpatia e compaixão são usados indiscriminadamente, sem que haja preocupação com os significados atribuídos ou com a superposição entre construtos.

Ainda no que se refere a essa questão, outra revisão feita por Duan e Hill (1996) indica a existência de três principais correntes de pensamento dentro da Psicologia: a primeira considera que a empatia se refere a um traço de personalidade ou habilidade geral para conhecer os estados mentais de outras pessoas e para sentir as emoções dos outros. Nesse caso, "supõe-se que alguns indivíduos são mais empáticos do que outros, seja por sua natureza, seja pelo seu desenvolvimento" (Duan \& Hill, 1996, p. 262).

Na segunda perspectiva, a empatia é vista como um construto que reflete respostas afetivocognitivas ligadas a situações específicas, sendo, portanto, mais disposicional do que constitucional. Uma proposição básica dessa perspectiva é a de que o nível de empatia varia de momento para momento, e que o estudo de fatores situacionais é mais importante do que a investigação de aspectos estruturais/constitucionais. Segundo Strayer (1987), uma abordagem multidimensional do construto de empatia deve focalizar a atenção nos estímulos que se fazem mais salientes no momento em que a empatia é produzida. Esses estímulos tornam-se salientes para o observador porque são intensos, possuem significado, são diferentes de experiências familiares ao observador e são emocionalmente excitadores.
A terceira perspectiva é adotada por pesquisadores que se interessam pela forma como a empatia é vivenciada por terapeutas e clientes durante as sessões de psicoterapia. Esses pesquisadores consideram a empatia um processo experiencial com várias fases, que envolve uma série de elementos próprios ao setting terapêutico, como, por exemplo, os humores do terapeuta e do cliente e o próprio desenrolar da psicoterapia. Dentro dessa perspectiva, segundo Davis (2004), a empatia caracteriza-se como um tipo de resposta afetiva que, no setting terapêutico, ocorre ao longo de três etapas: na primeira, o psicoterapeuta escuta atentamente o cliente, tentando compreendê-lo cognitivamente, tomando sua perspectiva; na segunda, ocorre um aprofundamento emocional por parte do terapeuta, no sentido de que ele passa a ser tocado (sensibilizado) pelo que observa no relato do outro, e, por fim, na terceira etapa, esse aprofundamento produz um sentimento de unicidade com o cliente, e é essa sensação que, segundo Davis, caracteriza a empatia propriamente dita.

Além das discussões conceituais fomentadas por essas três perspectivas, existe na Psicologia outro intenso debate sobre o fato de a empatia refletir apenas aspectos de ordem cognitiva, em termos de processamento da informação, e/ou aspectos afetivos, relacionados ao conteúdo afetivo mobilizado no self. Os autores que defendem uma perspectiva puramente cognitivista (Dymond, 1949, 1950; Wispé, 1986) acreditam que o construto da empatia reflita uma capacidade ou habilidade cognitiva de compreender os pensamentos, sentimentos ou intenções de outras pessoas, e "que, se afetos são produzidos na experiência da empatia, ocorrem como um epifenômeno da cognição" (Strayer, 1987, p. 153).

Nessa direção, Dymond definia a empatia como uma capacidade de "transposição imaginativa de si no pensamento, sentimento e ações do outro" (Dymond, 1949, p. 127), e a 
investigava comparando a avaliação que uma pessoa (A) fazia dela mesma com a avaliação que outra (B) fazia dela (A), bem como com a avaliação que $A$ fazia de B comparada à auto-avaliação de $\mathrm{B}$, determinando um índice que, segundo essa autora, designaria o nível de empatia dos indivíduos. Assim, para Dymond, o indivíduo mais empático era aquele que conseguia prever ou inferir com maior grau de precisão o que as outras pessoas sentiam e pensavam, mesmo que não fosse mobilizado afetivamente por esse conhecimento.

Compreende-se que a definição de Dymond (1949) corresponde a uma visão restrita da empatia, que, além de compartimentalizar as experiências vicárias interpessoais em aspectos cognitivos e afetivos, atribui importância apenas aos primeiros, como se os últimos fossem produtos unicamente do processamento de informações ocorrido durante os episódios empáticos. A nosso ver, a noção de empatia proposta por Dymond designa apenas uma capacidade cognitiva (tomada de perspectiva) que pode influenciar a natureza das experiências emocionais empáticas, mas que não equivale à empatia propriamente dita.

Por outro lado, alguns autores consideram que a empatia se refira a uma resposta emocional vicária às reações emocionais de outras pessoas (Feshback \& Roe, 1968; Mehrabian \& Epstein, 1972). Para eles, tanto o reconhecimento dos sentimentos e pensamentos dos outros como o compartilhar de seus estados afetivos são considerados elementos constituintes e indissociáveis da empatia. Nessa perspectiva, a empatia é vista como uma capacidade desenvolvida ao longo dos anos que tende a ser refinada à medida que os aspectos cognitivos e afetivos evoluem.

Mais recentemente, Enz e Zoll (2006) destacaram a existência de uma perspectiva alternativa para a compreensão e o estudo da empatia, que propõe a existência de aspectos ideomotores nas respostas empáticas. Baseados no princípio ideomotor de William James, esses autores estabeleceram a hipótese de que, ao observar os movimentos de outra pessoa, os neurônios-espelho localizados no córtex sensorial poderiam disparar e pré-ativar o córtex motor do observador, deixando-o predisposto a agir e até mesmo a executar, subliminarmente, movimentos semelhantes àqueles da pessoa observada. Esse tipo de reação teria repercussões importantes para a produção da empatia, pois essa pré-ativação do sistema motor teria o potencial de deixar o observador apto a sentir emoções "similares às emoções que produziram os movimentos na pessoa alvo, ou à emoção que é expressa... (pela pessoa observada)" (Enz \& Zoll, 2006, p. 4).

Essa teoria encontra forte apoio empírico no modelo teórico chamado de Perception Action Model (PAM), que ajuda a explicar os mecanismos neurológicos que possibilitam aos humanos compartilhar representações e sentimentos dos seus semelhantes através da percepção (Decety \& Jackson, 2004; Preston \& De Waal, 2002). Estudos com neuroimagens funcionais indicam que alguns circuitos neuronais do córtex pré-motor, do lóbulo parietal e da área motor suplementar que são ativados quando o sujeito executa uma ação também são ativados quando ele percebe que outrem realiza essa mesma ação, o que reforça a hipótese acerca da existência de um componente ideomotor na empatia.

Dessa forma, para autores como Decety e Jackson (2004), a empatia seria uma experiência fenomênica unicamente humana e teria bases evolutivas. Estas seriam compostas por elementos cognitivos (tomada de perspectiva, autoconsciência, reconhecimento e compreensão dos estados mentais das outras pessoas, etc.) e afetivos, cujas bases funcionais poderiam ser identificadas a partir da atividade integrada de diversos sistemas corticais. 
Decety e Jackson revelam ainda que estudos recentes demonstram haver uma relação entre lesões na região pré-frontal do córtex, especialmente a localizada no hemisfério direito, e a capacidade de sentir empatia pelas outras pessoas. Conforme sugerem os estudos de Damasio (1996/2007) e a revisão feita por Preston e De Waal (2002), a explicação para esse aparente déficit pode estar ligado ao fato de que algumas regiões do córtex pré-frontal estão altamente relacionadas a mecanismos autoregulatórios da vida em sociedade (Butman \& Allegri, 2001) e à capacidade de tomada de perspectiva, os quais são importantes componentes da empatia.

Ainda no que se refere aos substratos neurológicos da empatia, outros estudos indicam que a observação de expressões faciais ativa, em um nível subliminar, as mesmas expressões faciais no observador (Preston \& De Waal, 2002), mesmo que ele não tenha consciência disso. Ademais, expressar intencionalmente uma emoção aumenta intensamente a atividade no sulco temporal superior, ínsula, amígdala e córtex motor, áreas que estão altamente envolvidas nas experiências emocionais (Moll et al., 2001). Nesse sentido, a ressonância afetiva que ocorre durante os episódios empáticos pode estar relacionada à capacidade humana de reconhecer e imitar expressões faciais e gestuais e aos mecanismos neurológicos subjacentes a essas funções.

Considerando os problemas decorrentes das divergências teórico-conceituais supracitadas, a aproximação entre áreas como a Psicologia (desenvolvimento, social, cognitiva e evolutiva) e as neurociências pode representar um caminho importante a ser seguido nos próximos anos. Assim, compreende-se que uma definição clara do que se tem em mente quando se fala em empatia e o desenvolvimento de métodos de investigação mais precisos são de fundamental importância para a compreensão das bases evolutivas, sociais e neurológicas da empatia, assim como para a articulação dos conhecimentos produzidos nas áreas supracitadas.

\section{A investigação empírica da empatia}

Ao longo dos anos, a empatia tem sido pesquisada através de uma série de instrumentos, dentre os quais se destacam os que envolvem a utilização de índices fisiológicos (verificação da condutibilidade e da temperatura da pele e monitoramento das freqüências cardíaca e respiratória), índices somáticos (análise das expressões faciais e dos gestos), histórias ilustradas (por fotos, figuras ou gravações em vídeo), questionários e escalas de auto-avaliação e, mais recentemente, neuroimagens funcionais.

Ao discutir a utilização dessas estratégias metodológicas, Strayer (1987) considera que métodos que avaliam a empatia através de índices fisiológicos são desvantajosos por estarem relacionados à excitação fisiológica geral, sem que haja certeza sobre o tipo de emoção que está sendo vivenciada. Segundo Strayer, medidas baseadas na análise da expressividade facial superam essa dificuldade, uma vez que juízes altamente treinados seriam capazes de diferenciar tipos de emoções a partir das expressões faciais de uma pessoa (p. 234). Além disso, as expressões faciais não apenas retratariam o tipo de emoção que está sendo vivenciado como também influenciariam a maneira como a pessoa que as expressa se sente, pois as emoções são intensificadas quando são facialmente expressas e vice-versa.

Conforme citam Decety e Jackson (2004), pesquisas demonstram que expressões faciais são potentes estimuladores emocionais, pois produzem no observador emoções similares às que estão sendo expressas por 
quem é observado. Além disto, imitar expressões emocionais pode fazer com que o sujeito sinta as emoções correspondentes ao que está sendo imitado, mesmo que nenhum estímulo eliciador de emoções esteja presente naquele momento (Butman \& Allegri, 2001). Nesse sentido, além de funcionar como instrumento de investigação dos aspectos emocionais da empatia, as expressões faciais podem ser utilizadas para estimular reações emocionais vicárias em sujeitos experimentais.

De maneira geral, estudos nos quais se utilizam índices somáticos e fisiológicos para acessar a empatia têm-se mostrado muito úteis em diminuir os efeitos negativos que a expectativa social pode exercer sobre as respostas dos sujeitos de pesquisa (Eisenberg, Fabes, Bustamante, \& Mathy, 1987; Krebs, 1975; Marcus, 1987; Preston \& De Waal, 2002). Contudo, esse tipo de técnica traz algumas desvantagens, como, por exemplo, a necessidade de se utilizar aparelhos muito caros e incômodos para os participantes. Além disso, o manuseio de tais aparelhos e as análises dos dados produzidos requer um alto grau de especialização por parte do pesquisador. Outra desvantagem desse tipo de método é que a interpretação dos dados requer, também por parte do pesquisador, maior grau de inferência em relação aos diferentes tipos de reações afetivas produzidas durante a pesquisa.

Já os métodos que envolvem a utilização de histórias ilustradas, escalas ou questionários têm a vantagem de produzir dados que são condizentes com a experiência subjetiva dos respondentes, consomem menos tempo e dinheiro e exigem menos treinamento por parte dos pesquisadores (Bryant, 1987; Strayer, 1987), além de poderem ser aplicados a grandes amostras e de serem rapidamente analisados. Por outro lado, os métodos que utilizam essas técnicas possuem algumas desvantagens, como, por exemplo, não abordarem outras dimensões envolvidas na produção da empatia (comportamento não-verbal, pressões situacionais ligadas à expectativa social, etc.). Além disso, esse tipo de técnica pode ser bastante influenciado por alguns fatores, como a vergonha de falar sobre suas emoções a um estranho, a possibilidade de que os respondentes não sejam lingüisticamente hábeis para relatar o que estão sentindo, ou sejam incapazes de entender as instruções que lhes são fornecidas, e dificuldades na utilização de números para mensurar experiências subjetivas, dentre outras (Batson, 1987).

Para os pesquisadores que consideram a empatia como uma variável constitucional ou traço disposicional, as duas medidas mais conhecidas são o Questionaire Measure of Emotional Empathy, de Mehrabian e Epstein (1972), e o Interpessonal Reactivity Index (IRI), de Davis (1983). A primeira consiste em uma escala que combina diversos itens de responsividade afetiva nos domínios da empatia ou da simpatia. $\mathrm{O}$ instrumento de Davis, por sua vez, aborda a empatia de maneira multidimensional, através de um questionário com duas subescalas afetivas (personal distress e empathic concern) e duas subescalas cognitivas (role-taking e fantasy).

Além do IRI e do questionário de Mehrabian e Epstein, Del Giudice (2004) cita a Affective Perspective-taking Task (Denham, 1986), o Interpersonal Perception Test - IPT (Borke, 1971), o Feshbach Affective Situation Test for Empathy - FASTE (Feshbach \& Roe, 1968), o Empathy Continuum Scoring System ECSS (Strayer, 1987), o Index of Empathy for Children and Adolescent (Bryant, 1982), a Empathy Scale (Hogan, 1969) e o teste How I Feel in Different Situations como importantes instrumentos utilizados para mensurar a empatia e a capacidade de tomada de perspectiva. Os cinco primeiros são utilizados em crianças cujas idades podem variar de 3 a 8 anos de idade, o sexto com crianças e 
adolescentes, e o último é aplicável apenas a indivíduos adultos.

Considera-se que o IRI seja um instrumento mais completo que os demais justamente por considerar a empatia um construto multidimensional, avaliando-a através de subescalas afetivas e cognitivas que apresentam boa consistência interna. O IRI tornou-se um instrumento reconhecido e amplamente utilizado por pesquisadores de diversos países (Escrivá, Navarro, \& Garcia, 2004), inclusive orientais (Siu \& Sheck, 2005), tendo sido validado (Ribeiro, Koller, \& Camino, 2002) e utilizado eficazmente inclusive em amostras brasileiras (Sampaio, Monte, Camino, \& Roazzi, 2008; Soares, 1996).

Considerando as vantagens e desvantagens apresentadas pelas diferentes maneiras de se acessar a empatia, Strayer e Eisenberg (1987) julgam que técnicas mais aperfeiçoadas e acuradas de investigação implicam a utilização de abordagens multidimensionais, e que esse avanço implicará a necessidade de maior clareza conceitual e a produção de dados mais precisos. Contudo, essas autoras alertam para o fato de que utilizar diversas medidas fracas em um mesmo estudo não tem nenhum tipo de vantagem, se comparado à utilização bem controlada de um único tipo de medida.

Ademais, como indica o trabalho de Del Giudice (2004), a criação de diversos tipos de instrumentos não implica, necessariamente, maior nível de precisão conceitual e metodológica, visto que a utilização e a validação de muitos desses instrumentos têm sido questionadas por diversos estudos. Entre as principais críticas levantadas contra as escalas supracitadas, destacam-se a falta de consistência interna de algumas subeescalas (empathy scale), a mensuração estereotipada da capacidade de antecipar reações afetivas, mais do que da capacidade de descentração
(IPT), e a falta de especificidade acerca do tipo de reação afetiva/empática que está sendo mensurada (FASTE).

Métodos que utilizam imagens funcionais do cérebro, evocação de potencial em microeletrodos e estimulação magnética transcraniana são exemplos de técnicas de investigação utilizadas atualmente na pesquisa sobre empatia e que têm produzido importantes insights sobre os diferentes sistemas corticais envolvidos nas experiências empáticas (Damasio, 1996/2007; Decety \& Jackson, 2004; Moll et al., 2001). Dados importantes têm sido produzidos também a partir do estudo com pacientes autistas, sociopatas e esquizofrênicos (Preston \& De Waal, 2002), indicando haver relação entre prejuízos em habilidades sociocognitivas e o comprometimento de determinados circuitos neuronais.

No que diz respeito ao campo de estudos sobre a empatia na atualidade, existem poucos trabalhos empíricos nessa área, sendo que, nas últimas décadas, parece ter havido um desinteresse crescente dos pesquisadores em investigar esse processo (Duan \& Hill, 1996). Essa "desaceleração" dos estudos sobre a empatia estaria baseada, principalmente, na aparente falta de acordo sobre as questões conceituais, metodológicas e empíricas apresentadas ao longo dos anos. Apesar desses problemas, alguns pesquisadores desenvolveram estudos nos quais buscaram investigar a relação entre a empatia, o sexo, a idade e a cultura, a fim de compreender como aspectos contextuais e desenvolvimentistas influenciavam essa e outras reações afetivas vicárias, algumas das quais serão apresentadas a seguir.

\section{Estudos empíricos sobre a empatia}

Considerando que a empatia seja uma resposta afetiva cujo processo de desenvolvimento é 
influenciado pelo contexto sociocultural, alguns autores têm buscado verificar se pessoas de diferentes países demonstram diferenças quantitativas e/ou qualitativas no que diz respeito às experiências empáticas. Dentre eles, destacam-se os trabalhos de Enz e Zoll (2006) e o de Siu e Sheck (2005).

Segundo Enz e Zoll, apenas cinco estudos investigaram diferenças transculturais da empatia, dentre os quais se destaca o de Trommsdorff (1995), que comparou amostras de sujeitos da Alemanha e do Japão. Enz e Zoll afirmam que as dificuldades para realizar estudos transculturais são decorrentes, sobretudo, de alguns fatores, como o pouco conhecimento que se tem acerca do desenvolvimento da empatia, a carência de investigações a respeito da influência de aspectos culturais sobre os processos psicológicos ligados à afetividade, além da existência de diversos problemas conceituais no campo, conforme visto anteriormente. No caso particular do estudo de Trommsdorff, Enz e Zoll apontaram, por exemplo, que o instrumento utilizado foi desenvolvido na Alemanha e não passou por nenhuma adaptação ao contexto cultural da China.

Considerando algumas dessas questões, Enz e Zoll (2006) realizaram uma pesquisa transcultural da qual participaram 252 crianças de Portugal $(n=55)$, Alemanha $(n$ =96) e Reino Unido $(n=101)$, de ambos os sexos e com idades variando entre 8 e 14 anos. A outra parte da amostra foi composta por 200 crianças chinesas de ambos os sexos e com idades variando de 7 a 13 anos. Para investigar os níveis de empatia dos participantes, foi desenvolvido um instrumento baseado na Escala de Bryant (1982) e utilizado um outro, desenvolvido por um pesquisador alemão, que foi adaptado às especificidades culturais de cada país.

De maneira geral, os resultados do estudo de Enz e Zoll demonstraram que as crianças chinesas se descreveram como mais empáticas (na dimensão afetiva) do que as crianças dos outros países, com o inverso sendo verdadeiro para as crianças germânicas. Quanto aos aspectos cognitivos da empatia, observaram que as crianças do Reino Unido pontuaram mais alto que as crianças dos outros países nesses itens. Diferenças de gênero também foram identificadas neste estudo, pois as meninas se descreveram como mais empáticas do que os meninos nos quatro países.

Em outro estudo, Siu e Sheck (2005) aplicaram uma versão traduzida e adaptada do IRI a uma amostra de estudantes secundaristas e universitários de uma região industrializada da China com o intuito de testar as propriedades psicométricas do instrumento naquele país. É interessante destacar que, apesar das análises fatoriais confirmatórias corroborarem o modelo de Davis (1983), análises exploratórias revelaram que um modelo com três e não quatro fatores era mais adequado para explicar os dados. No primeiro fator, predominaram os itens referentes à subescala de personal distress; no segundo, as questões relativas à dimensão de fantasy, e, no terceiro fator, houve um agrupamento dos itens das subescalas de empathic concern e perspective taking.

Esses resultados sugerem que, para os jovens chineses, pode não ter havido distinção entre os componentes cognitivos e afetivos da empatia tal como eles são mensurados no IRI, o que justifica o agrupamento desses itens em um único fator. Além disso, Siu e Sheck destacaram que esses resultados intensificam ainda mais o debate sobre a existência de fronteiras bem delimitadas entre os processos de tomada de perspectiva e as experiências afetivas vivenciadas na empatia e sobre a relação entre esses fenômenos.

Em uma interessante revisão sobre pesquisas que focalizaram as diferenças de gênero e 
idade na empatia, Lennon e Eisenberg (1987) julgaram que a interpretação dos resultados desses estudos não produzia conclusões consensuais, já que alguns indicavam a existência de diferenças, enquanto outros não. No caso das diferenças de gênero encontradas, os autores identificaram claramente a influência dos métodos utilizados para acessar a empatia: em situações nas quais os participantes tinham controle consciente sobre suas respostas e as demandas situacionais eram elevadas, as diferenças tenderam a ser mais acentuadas. Todavia, quando as demandas características eram mais sutis, as diferenças tenderam a ser menos acentuadas. Além disso, quando as demandas eram mais sutis e os participantes não tinham controle consciente de suas respostas, nenhuma diferença de gênero foi observada.

Apesar de ainda não haver consenso na literatura a respeito da natureza real das diferenças de gênero observadas nos estudos sobre a empatia, estudos que se utilizam de escalas auto-avaliativas (Eisenberg, 2000; Enz \& Zoll, 2006; Escrivá et al., 2004; Ribeiro et al., 2002; Sampaio et al., 2008; Siu \& Sheck, 2005; Soares, 1996) têm demonstrado, consistentemente, que as mulheres atingem escores mais elevados que os homens em subescalas afetivas de empatia, ou seja, elas se descrevem como mais empaticamente sensíveis que eles. Por outro lado, não se observam diferenças significativas entre homens e mulheres em subescalas relacionadas a componentes cognitivos da empatia, como a tomada de perspectiva.

Pode-se supor que essas diferenças sejam produzidas por conta da utilização de instrumentos auto-avaliativos, que tendem a sofrer influências da expectativa social e das representações que os participantes têm a respeito dos papéis sociais atribuídos a homens e a mulheres na sociedade. Outra interpretação que se pode fazer desses resultados é de que as diferenças observadas ocorreram por conta da falta de clareza a respeito das reações afetivas acessadas nas pesquisas, pois, em alguns estudos, quando os instrumentos avaliavam contágio emocional, não houve diferenças evidentes, mas quando eles objetivavam avaliar a empatia, as mulheres se revelaram mais emocionalmente reativas do que os homens (Lennon \& Eisenberg, 1987).

No que se refere às mudanças em função da idade, a revisão de Lennon e Eisenberg (1987) mostra uma variação relacionada ao tipo de índice utilizado na avaliação da empatia. Auto-relatos sobre as emoções sentidas, por exemplo, quando se inferem os afetos de outras pessoas, parecem aumentar com avanços na idade até a metade do processo de escolarização. Por outro lado, índices que se baseiam em expressões faciais e nos gestos parecem estar inversamente relacionados, ou até mesmo não relacionados ao aumento da idade durante os anos escolares.

Lennon e Eisenberg (1987) afirmam que, de maneira geral, os diferentes resultados de pesquisa são difíceis de ser interpretados e sinalizam a possibilidade de que diferentes reações emocionais tenham cursos de desenvolvimento diferenciados. Diante disso, esses autores apontaram a importância de serem elaboradas pesquisas que primem pela precisão conceitual e metodológica para que os significados do modelo de diferenças de gênero e idade na empatia possam ser mais bem esclarecidos.

Outros estudos (Coke et al., 1978) demonstraram que, para os indivíduos com elevados níveis de empatia, a freqüência de comportamentos de ajuda se mantém alta, mesmo que nenhuma outra pessoa (até mesmo a pessoa necessitada que irá receber a ajuda) esteja sabendo daquela ação. Esses dados sugerem que a questão da 
desejabilidade social tem pouca influência sobre o comportamento de ajuda quando o indivíduo está altamente motivado pela empatia. Além disso, nos estudos nos quais se utilizou um delineamento experimental cujos condicionantes eram a empatia (alta ou baixa) e a facilidade para escapar da situação (alta ou baixa), observou-se que, quando a empatia era alta, a freqüência com que se ajudava era também alta, independentemente da facilidade para escapar da situação (Batson et al., 1981). Em contrapartida, observou-se que, quando a empatia era baixa, a freqüência do comportamento de ajuda era alta apenas quando a possibilidade de fugir da situação era baixa.

Partindo do pressuposto de Hoffman (1991) de que maiores níveis de empatia podem predispor um indivíduo a aderir mais facilmente aos princípios do cuidado, necessidade e esforço, e interessados em investigar qual a relação entre a resposta vicária e a habilidade de tomada de perspectiva, Camino e Camino (1996) entrevistaram 222 crianças, que foram divididas em dois grupos etários (5 a 7 anos e 8 a 10 anos). Utilizando pequenas histórias, esses pesquisadores manipularam as seguintes variáveis: intencionalidade do personagem principal (sem intenção, intenção altruísta, intenção hostil), as ações desse personagem (agressivas ou de roubo) e a gravidade das conseqüências da ação (mais grave ou menos grave).

Nos resultados, Camino e Camino (1996) observaram que havia aumento na capacidade de atribuir corretamente as emoções dos outros em função da idade. Observaram também que essa capacidade estava relacionada ao julgamento moral para os dois grupos etários. Outros resultados demonstraram uma progressão na empatia inferencial e no escore global de empatia em função da idade, no sentido que, quanto mais velhas, mais as crianças se identificavam com o personagem altruísta. Por fim, os dados mostraram haver uma relação entre empatia inferencial e julgamento moral, pois as crianças que sentiram empatia pelo personagem altruísta deram mais respostas certas (ao avaliar quem era o personagem mais vil) do que as que não sentiram empatia por ele.

\section{Considerações finais}

A empatia, assim como outras experiências afetivas vicárias, tem sido objeto de interesse de diversos campos do saber ao longo dos anos. Os estudos apresentados na presente revisão focalizaram os aspectos interindividuais envolvidos nas experiências empáticas, ressaltando sua importância para a psicoterapia, o desenvolvimento de habilidades cognitivo-afetivas e a vida em sociedade.

Apesar das divergências conceituais e metodológicas envoltas nessa temática, existe consenso entre os teóricos a respeito da forte influência que a empatia pode exercer nos processos de tomada de decisão, especialmente quando esta se refere a questões ligadas ao cuidado, respeito e moralidade. Por outro lado, constatou-se que a avaliação causal da situação, bem como de outras habilidades cognitivas (principalmente a capacidade de tomada de perspectiva), tem potencial para mediar e influenciar as respostas afetivas que serão experienciadas no self. Outros dados sugerem haver diferentes tipos de afetos quando o indivíduo experiencia aquilo que os pesquisadores têm chamado de episódios empáticos.

Mais especificamente, os dados de pesquisa indicam a existência de sentimentos de perturbação e desconforto que são sentidos no self quando se observa alguém sofrendo, em perigo ou desvantagem. Todavia, observa- 
se também que, diante do sofrimento de alguém, as pessoas podem sentir piedade, compaixão e um desejo claro de ajudar quem está sofrendo, o que indica a existência de diferenças qualitativas nas respostas emocionais da empatia e reforça a tese de que a empatia deve ser compreendida como um construto multidimensional.

No que se refere à realidade do Brasil, a pesquisa feita por Sampaio (2007) em importantes portais de pesquisa do País (BVS-Psi e SciELO) indica que há uma carência de estudos sobre os componentes constituintes da empatia e sobre suas relações com aspectos evolutivos, sociais, desenvolvimentistas e neurológicos. Indica ainda que faltam instrumentos de avaliação da empatia adaptados à cultura brasileira, destacando que apenas a escala de Bryant (1982) e a de Davis (1983) foram validadas em nosso país.

Ademais, trabalhos como os de Eisenberg (Eisenberg, 2000; Eisenberg et al., 2001) e de Batson (Batson et al., 2003) demonstram que as experiências empáticas constituem um importante componente da vida em sociedade e que o refinamento teórico- conceitual e metodológico na investigação dessas experiências é condição necessária para o crescimento qualitativo nesse campo de estudos. A realização de mais pesquisas voltadas para esse objetivo, além de promover um aprofundamento na compreensão sobre o desenvolvimento cognitivo-afetivo, poderá subsidiar a realização de programas de intervenção voltados para promover o aumento de habilidades socio-afetivas e a evolução de julgamentos e comportamentos morais. Consideram-se importantes não apenas a realização de pesquisas no campo da empatia mas também a elaboração de estudos sobre as relações entre empatia e moralidade, os quais poderão testar as hipóteses de autores como Hoffman e Batson e contribuir fortemente para o campo da educação moral.

Por fim, concordamos com autores como Preston e De Waal (2002) e Decety e Jackson (2004), que afirmam que a aproximação entre os campos da Psicologia (social, desenvolvimento e cognitiva), teoria evolutiva e neurociências representa o caminho a ser seguido nos próximos anos, para que se consiga o refinamento teórico-metodológico necessário ao crescimento qualitativo do campo de estudos da empatia. 


\section{Referências}

\section{Leonardo Rodrigues Sampaio*}

Doutor em Psicologia cognitiva. Professor e pesquisador do Colegiado de Psicologia da Universidade Federal do Vale do São Francisco - UNIVASF.

\section{Cleonice Pereira dos Santos Camino}

Doutora em Psicologia. Professora do Programa de Pós-graduação em Psicologia Social da Universidade Federal da Paraíba - UFPB, coordenadora do Núcleo de Pesquisas sobre Desenvolvimento Sócio-Moral.

E-mail: cleocamino@yahoo.com.br

\section{Antonio Roazzi}

Doutor em Psicologia. Professor e pesquisador do Programa de Pós-graduação em Psicologia Cognitiva da Universidade Federal de Pernambuco - UFPE.

E-mail: roazzi@gmail.com

\section{*Endereço para envio de correspondência:}

Universidade Federal do Vale do São Francisco - UNIVASF

Av. José de Sá Maniçoba, s/n. Centro. Petrolina - PE - Brasil, CEP: 56304-250.

E-mail: leorsampaio@yahoo.com.br

Recebido 01/02/2008 Reformulado 21/01/2009 Aprovado 10/02/2009

Baldwin, J. M. (1913). History of psychology: A sketch and an interpretation. Recuperado em 17 de dezembro de 2007 de Classics in the history of Psychology: http://psychclassics. yorku.ca/

Batson, C. D. (1987). Self-report rating of empathic emotion. In N. Eisenberg \& J. Strayer (Eds.), Empathy and its development (pp. 356-360). New York: Cambridge University Press.

Batson, C. D., Duncan, B. D., Ackerman, P., Buckley, T., \& Birch, K. (1981). Is empathic emotion a source of altruistic motivation? Journal of Personality and Social Psychology, 40(2), 290-302.

Batson, C.D., Fultz, J., \& Schoenrade, P. A. (1987). Distress and empathy: Two qualitatively distinct vicarious emotions with different motivational consequences. Journal of Personality, 55(1), 21-75.

Batson, C. D, Lishner, D. A., Carpenter, A., Dulin, L., HarjusolaWebb, S., Stocks, E. L. et al. (2003). “... As you would have them do unto you": Imagining yourself in the other's place stimulate moral action? Personality and Social Psychology Bulletin, 29(9), 1190-1201.

Borke, H. (1971). Interpersonal perception of young children: Egocentrism or empathy? Developmental Psychology, 5, 263-296.
Bryant, B. K. (1982). An index of empathy for children and adolescent. Child Development, 53, 413-425.

Bryant, B. K. (1987). Critique of comparable questionnaire methods in use to access empathy in children and adults. In N. Eisenberg \& J. Strayer (Eds.), Empathy and its development (pp. 361-373). New York: Cambridge University Press.

Butman, J., \& Allegri, R. F. (2001). A cognição social e córtex cerebral. Psicologia: Reflexão e Crítica, 14(2), 275-279.

Camino, C., \& Camino, L. (1996). Julgamento moral, emoção e empatia. In Z. D. Trindade \& C. Camino (Eds.), Cognição social e juízo moral (Coletâneas da ANPEPP, pp. 109-135). Rio de Janeiro: Associação Nacional de Pesquisa e Pós-graduação em Psicologia.

Coke, J. S., Batson, D. C., \& McDavis, K. (1978). Empathic mediation of helping: A two-stage model. Journal of Personality and Social Psychology, 36(7), 752-766.

Damasio, A. R. (2007). O erro de Descartes: emoção, razão e o cérebro humano. São Paulo: Companhia das Letras. (Trabalho original publicado em 1996)

Davis, C. M. (2004). What is empathy, and can it be taught? Physical Therapy, 70(11), 707-713. 
Davis, M. H. (1983). Measuring individual differences in empathy: Evidence for a multidimensional approach. Journal of Personality and Social Psychology, 44, 113-136.

Decety, J., \& Jackson, P. L. (2004). The functional architecture of human empathy. Behavioral and Cognitive Neuroscience Review, 3(2), 71-100.

Del Giudice, M. (2004). Misurare le emozioni - Una rassegna de test più utilizzati nella ricerca sulle emozioni: caractteristiche, funzionamento, risultati empririci. 2004. Recuperado em 15 de junho de 2005, de www.psych.unito.it/csc/pers/delgiudice/ pdf/Mis_emo_04.pdf

Denham, S. A. (1986). Social cognition, prosocial behavior and emotion in preschoolers: Contextual validation. Child Development, 57, 194-201.

Duan, C., \& Hill, C. E. (1996). The current state of empathy research. Journal of Counseling Psychology, 43(3), 261-274.

Dymond, R. F. (1949). A scale for the measurement of empathic ability. Journal of Consulting and Clinical Psychology, 13, 127-133.

Dymond, R. F. (1950). Personality and empathy. Journal of Consulting Psychology, 14, 343-350

Eisenberg, N. (2000). Emotion, regulation and moral development. Annual Review of Psychology, 51, 665-697.

Eisenberg, N., Fabes, R. A., Bustamante, D., \& Mathy, R. M (1987). Physiological indices of empathy. In N. Eisenberg, J. Strayer (Eds.), Empathy and its development (pp. 380-385). New York: Cambridge University Press.

Eisenberg, N., Zhou, O., \& Koller, S. (2001). Brazilian adolescents' prosocial moral judgment and behavior: Relations to sympathy, perspective taking, gender-role orientation, and demographic characteristics. Child Development, 72(2), 518-534.

Enz, N., \& Zoll, N. (2006). Cultural differences in empathy between China, Germany and the UK. Recuperado em 23 de novembro de 2006, de www.nicve.salford.ac.uk/elvis/ resources/empathy

Escrivá, V. M., Navarro, M. D. F. \& Garcia, P. S. (2004). La medida de la empatía: Análisis del interpersonal reactivity index. Psicothema, 16(2), 255-260.

Feshbach, N. D., \& Roe, K. (1968). Empathy in six-and sevenyear-olds. Child Development, 39, 133-145.

Hoffman, M. L. (1987). The contribution of empathy to justice and moral judgment. In N. Eisenberg, \& J. Strayer (Eds.) Empathy and its development (pp. 47-79). New York: Cambridge University Press.

Hoffman, M. L. (1989). Empathy, role-taking, guilt and development of altruistic motives. In N. Eisenberg, Reykowski, \& E. Staub (Eds.), Social and moral values: Individual and societal perspectives (pp. 139-152). Hillsdale, NJ: Erlbaum.

Hoffman, M. L. (1991). Empathy, social cognition and moral action. In W. M. Kurtines \& J. L. Gewirtz (Eds.), Handbook of moral behavior and development (pp. 65-87). New Jersey: LEA

Hogan, R. (1969). Development of an empathy scale. Journal of Consulting and Clinical Psychology, 33, 307-316.

Krebs, D. (1975). Empathy and altruism. Journal of Personality and Social Psychology, 32(6), 1134-1146.

Lennon, R., \& Eisenberg, N. (1987). Gender and age differences in empathy and sympathy. In N. Eisenberg \& J. Strayer (Eds.),
Empathy and its development (pp. 195-217). New York: Cambridge University Press.

Marcus, R. J. (1987). Somatic indices of empathy. In N. Eisenberg \& J. Strayer, J. (Eds.), Empathy and its development (pp. 374379). New York: Cambridge University Press.

Mehrabian, A., \& Epstein, N. (1972). A measure of emotional empathy. Journal of Personality, 40, 525-543.

Moll, J., Oliveira-Souza, R., Miranda, J. M., Bramanti, I. E., Veras, R. P., \& Magalhães, A. C. (2001). Efeitos distintivos da valência emocional positiva e negativa na ativação cerebral. Revista Brasileira de Psiquiatria, 23, 42-46.

Murphy, L. B. (1937). Social behavior and child personality: An exploratory study of some roots of sympathy. New York: Columbia University Press.

Preston, S. D., \& De Waal, F. M. M. (2002). Empathy: Its ultimate and proximate bases. Behavioral and Brain Sciences, 25, 1-72.

Ribeiro, J., Koller, S. H., \& Camino, C. (2002). Adaptação e validação de duas escalas de empatia para uso no Brasil. Estudos de Psicologia, 18(3), 43-53.

Rogers, C. R. (2001a). Sobre o poder pessoal (4a ed., W. M. Alves Penteado, trad.). São Paulo: Martins Fontes. (Trabalho original publicado em 1979

Rogers, C. R. (2001b). Tornar-se pessoa (5a ed., M. J. C Ferreira \& A. Lamparelli, trads.). São Paulo: Martins Fontes. (Trabalho original publicado em 1985)

Sampaio, L. R. (2007). Produtividade, necessidade e empatia: relações entre julgamentos distributivos, consideração empática e tomada de perspectiva. Tese de Doutorado, Programa de Pós-Graduação em Psicologia Cognitiva, Universidade Federal de Pernambuco, Recife.

Sampaio, L. R., Monte, F. C., Camino, C., \& Roazzi, A. (2008). Justiça distributiva e empatia em adolescentes do nordeste brasileiro. Psicologia: Reflexão e Crítica, 21(2), 275-282.

Siu, A. M. H., \& Shek, D.T. L. (2005). Validation of the interpersonal reactivity index in a Chinese context. Research on Social Work Practice, 15(2), 118-126.

Soares, J. F. R. (1996). O julgamento moral, a tomada de perspectiva do outro e a consideração empática: um estudo correlacional. Dissertação de Mestrado em Psicologia Social, Universidade Federal da Paraíba, João Pessoa.

Strayer, J. (1987). Picture-story indices of empathy. In N. Eisenberg \&J. Strayer (Eds.), Empathy and its development (pp. 351-355). New York: Cambridge University Press.

Strayer, J., \& Eisenberg, N. (1987). Empathy viewed in context. In N. Eisenberg, \& J. Strayer (Eds.), Empathy and its development (pp. 389-398). New York: Cambridge University Press.

Trommsdorff; G. (1995). Person-context relations as developmental conditions and prosocial action: A cross-cultural analysis. In T. A. Kindermann \& J. Valsiner (Eds.), Development of personcontext relations (pp. 113-146). Hillsdale, NJ: Erlbaum.

Wispé, L. (1986). The distinction between sympathy and empathy: To call forth a concept, a word is needed. Journal of Personality and Social Psychology, 50(2), 314-321.

Wispé, L. (1987). History of the concept of empathy. In N. Eisenberg \& J. Strayer (Eds.), Empathy and its development (pp. 17-37). New York: Cambridge University Press. 